\title{
El cabildo de Talca como cabecera de corregimiento y de subdelegación en la gobernación de Chile (segunda mitad del siglo XVIII)*
}

\section{Talca's cabildo as head of the Corregimiento and Subdelegation in the Government of Chile (late $18^{\text {th }}$ century)}

\author{
Lucrecia Enríquez \\ ORCID ID: htpps//orcid.org/0000-0002-7839-2652
}

Instituto de Historia, Pontificia Universidad Católica de Chile, Santiago, Chile

El artículo estudia comparativamente la vida capitular del cabildo de la villa de Talca (Chile) mientras fue cabecera de corregimiento y de subdelegación durante el siglo XVIII. El objetivo es desentrañar en ambos períodos la relación del cabildo como cuerpo con corregidores y subdelegados, con el fin de analizar de qué manera ejerció su prerrogativa de cabecera. En particular, buscamos analizar si a partir de la creación de la subdelegación del Maule, el gobierno del cabildo de Talca quedó circunscrito al gobierno del casco urbano, perdiendo así su jurisdicción en la totalidad del partido.

Palabras Clave: Intendencia; Subdelegación; Cabildo; Reformas borbónicas; Chile.

This article studies the life in the cabildo of Talca (Chile) when it was the capital of the corregimiento and of the subdelegations in the $18^{\text {th }}$ century. The objective was to unravel the relationship of the town council as a body with both corregidores and subdelegates with the purpose of analyzing in which way it exerted its prerogatives. This paper seeks to analyze whether, after the creation of the Maule sub-delegation, the ruling of the Talca cabildo was limited to the urban area, thus losing its jurisdiction over the entire partido.

KEYwords: Intendency; Sub-delegation; Cabildo, Bourbon Reforms; Chile.

Copyright: (C) 2021 CSIC. Este es un artículo de acceso abierto distribuido bajo los términos de la licencia de uso y distribución Creative Commons Reconocimiento 4.0 Internacional (CC BY 4.0).

* Este artículo forma parte del proyecto Fondecyt 1170714 «Los cabildos chilenos desde la reforma de intendencias a la declaración de la independencia en 1818», del que la autora es investigadora responsable. 


\section{Introducción}

En los últimos años se ha producido un cambio de óptica respecto a la comprensión del régimen de intendencias a partir de la revalorización de las subdelegaciones. ${ }^{1}$ En esta perspectiva, quisiéramos analizar en un cabildo de una villa cabecera de partido, Talca, la transformación que implicó el nuevo régimen territorial. Un tema que recorre el análisis de los cabildos en este período sostiene que, a partir del nuevo régimen de intendencias, los que eran cabecera de corregimiento perdieron jurisdicción a favor de los subdelegados, quedando restringidos al gobierno del casco urbano. Además, las relaciones entre cabildos y subdelegados habrían sido conflictivas. Nuestra propuesta consiste en analizar esta premisa por medio de la comparación de la relación del cabildo de Talca como cabecera con los corregidores y los subdelegados. Además, proponemos analizar el cambio que supuso en el cabildo de una villa cabecera, la citada Talca, la transformación de un corregimiento en subdelegación, con el fin de evaluar cómo se aplicó el nuevo régimen y qué lo diferenció de los corregimientos en un territorio concreto. Con esto queremos complementar el análisis estrictamente normativo circunscrito a una confrontación de facultades emanadas del análisis de la legislación.

Fundada en 1742, la villa no tuvo cabildo formal hasta 1759, cuando principian las actas. Esto pudo deberse al inicial proceso de establecimiento de la ciudad y al impacto del gran terremoto y maremoto de 1751, que derribó lo poco que se había construido. Además, el cabildo fue suspendido durante algunos años, por lo que la temporalidad de su funcionamiento en ambas etapas, corregimiento y subdelegación, permite la comparación. En cuanto al análisis de la subdelegación del Maule, se circunscribe al gobierno del subdelegado Vicente de la Cruz, ya que las actas del cabildo solo registran la vida capitular durante su gobierno, que se desarrolló entre 1788 y 1798. El siguiente subdelegado sólo aparece en las actas presidiendo las elecciones de alcaldes del año 1799. La siguiente acta es del año 1812, cuando ya no había subdelegados en el partido. Las fuentes que sustentan este estudio son las actas del cabildo, oficios intercambiados entre el subdelegado y el superior gobierno de Chile, y las consultas de la Cámara de Indias. Para comprender cómo se articularon las facultades de los corregidores y subdelegados con el cabildo, analizaremos en las actas del mismo el ejercicio de las facultades de ambos.

1 Enríquez, 2020a. 
Para todo ello, luego de dar cuenta de la bibliografía sobre el tema, analizaremos, en primer lugar, cómo se gobernaron los corregimientos en Chile, las facultades de sus titulares y cómo se interrelacionaron con los cabildos. A continuación, haremos el mismo ejercicio en el corregimiento del Maule y en la subdelegación del Maule, considerando la actuación del cabildo de Talca como cabecera con el fin de comparar los dos momentos. Analizaremos los cambios institucionales que la Real Ordenanza de Intendencias introdujo en los cabildos y en los gobiernos territoriales de los partidos a partir de la creación de las subdelegaciones. Nos detendremos en las facultades de intendentes y subdelegados en relación a los nuevos partidos y los cabildos, para analizar, finalmente, cómo esa transformación territorial tuvo su correlato en el cambio de Talca de villa a ciudad.

\section{Estado de la cuestión}

Carmen Palomo Souza señala para el caso de Zacatecas que el corregidor representaba el poder real ante el cabildo, ${ }^{2}$ afirmación que podemos hacer extensiva a Chile. Por su parte, Santiago Lorenzo, en su estudio sobre los corregidores en Chile en el siglo XVIII, distingue dos características que los diferenciaban de los corregidores peruanos: no practicaban los repartimientos de mercancías ni percibían sueldos. Señala también que los nativos del reino fueron quienes mayoritariamente ocuparon estos cargos. Según este autor, fue la falta de emolumentos lo que desarrolló una competencia entre el corregidor y las otras justicias del reino, por lo que, para monopolizar la administración de justicia, especialmente en el mundo rural, los corregidores lograron que los cabildos de las villas estuvieran suspendidos desde mediados del siglo XVIII, lo que se habría revertido hacia $1772 .{ }^{3}$ Lucrecia Enríquez, en su estudio sobre el restablecimiento de los cabildos chilenos a fines del siglo XVIII, comprobó que los corregidores los suspendieron porque no querían ningún otro poder que les hiciera contrapeso en su jurisdicción, por razones de cobro de los emolumentos provenientes de la administración de justicia. ${ }^{4}$

Respecto a la relación de los cabildos con los subdelegados, la bibliografía no abunda. Edberto Acevedo, en su estudio sobre las intendencias

2 Palomo Souza, 2005, 116.

3 Lorenzo, 1999.

4 Enríquez, 2019. 
altoperuanas, destacó que muchos subdelegados fueron de cuatro causas (policía, justicia, hacienda y guerra) por la gran cantidad de pueblos de indios, lo que las diferenció de las del resto del virreinato del Río de la Plata, en las que predominaron las de dos. También da cuenta de los conflictos entre subdelegados y cabildos, como el de Cochabamba, que pidió que se le aclararan las funciones judiciales de los subdelegados y cuáles conservaban las villas, lo que generó problemas de preeminencias. Algunos cabildos se quejaron ante el virrey de que los intendentes altoperuanos habían intentado advocar abogar la jurisdicción ordinaria en los subdelegados, ampliando a las cuatro causas la jurisdicción que tenían limitada a dos, llegando incluso a pedir al rey que así fuese declarado. En la subdelegación de Tarija, el intendente justificó que el subdelegado fuera de cuatro causas por el despotismo que siempre habían mostrado los alcaldes ordinarios, lo que derivó en largos pleitos. ${ }^{5}$

Laura Machuca ha estudiado la oposición fracasada del cabildo de Campeche tras la instalación de subdelegados en Yucatán. Para ello, denuncia que la historiografía previa que analizó la instalación de los subdelegados en la península los consideró perjudiciales para los ayuntamientos, dado que se redujeron las grandes extensiones de sus jurisdicciones territoriales, limitándose al casco urbano. Además, las ciudades habrían entrado en problemas de competencia jurisdiccional con intendentes y subdelegados. La autora contrarresta esta visión generalizadora y demuestra que los tres cabildos yucatecos no tuvieron una actitud uniforme frente al nuevo régimen. En efecto, el de Campeche fue el más afectado porque estuvo inmerso en luchas contra otros funcionarios reales que también limitaban sus facultades, dado que los subdelegados pertenecieron a la elite que controlaba el cabildo de Mérida y porque los límites impuestos al ejercicio de la justicia afectaban enormemente los intereses del mismo. Por tanto, fueron múltiples las razones de la oposición. ${ }^{6}$

Graciela Bernal ha estudiado cómo el cambio de jerarquía de la villa de San Luis de Potosí, convertida en cabecera de intendencia a partir de 1786 y asiento del intendente y su asesor letrado, no solo no provocó la debilidad del cabildo, sino que se consolidó como institución al relacionarse con las nuevas autoridades. ${ }^{7}$ La misma autora, junto a Blanca Briones, analizaron en Guanajuato el gobierno del intendente Andrés Amat de Tortosa,

5 Acevedo, 1992, 128 y 160-163.

6 Machuca, 2019, 222.

7 Bernal Ruiz, 2014. 
concluyendo que, gracias al apoyo de los subdelegados, pudo llevar a cabo las facultades de hacienda relativas a los ayuntamientos (solicitud y control de cuentas). En otro artículo, Graciela Bernal Ruíz toca otra arista de la relación entre cabildos y subdelegados en la intendencia de Guanajuato. Se trata de un enfrentamiento que el subdelegado de Celaya (apoyado por el cabildo) tuvo con el intendente por la confirmación de las elecciones de alcaldes. En este caso, el subdelegado era un alcalde mayor en ejercicio al momento de la puesta en vigencia de la Real Ordenanza de Intendencias, que continuó como subdelegado hasta completar su período de gobierno. Por eso interpretaba que la aprobación de alcaldes le correspondía al virrey, apoyándose en el artículo 11 de la real ordenanza, que señala que recaería la jurisdicción real de los corregimientos y alcaldías mayores en los intendentes como justicia mayor a medida que los primeros se fueran suprimiendo. Como señala la autora, este subdelegado continuó actuando como alcalde mayor pese al cambio de régimen. ${ }^{8}$

José Luis Alcauter sostuvo que el nombramiento de subdelegados provocó que los cabildos perdieran facultades en los partidos. Señala que, en la Nueva España, en el caso de ciudades y villas, los subdelegados que se nombraron fueron de cuatro causas, lo que generó conflictos con los ayuntamientos porque, al conocer los subdelegados las causas de policía y justicia en la jurisdicción de los cabildos, les restó poder e ingresos. Los conflictos se originaron en el doble incumplimiento tanto del artículo 11 de la real ordenanza que resguardaba que los alcaldes ordinarios conocieran en las cuatro causas, como del artículo 77 que preveía que se nombraran subdelegados de dos causas (hacienda y guerra) en ciudades y villas. De manera que los subdelegados allí nombrados tuvieron la jurisdicción y facultad de presidir los cabildos, que solo mantuvieron las facultades de justicia y policía en las cabeceras de partidos, consolidándose así la autoridad real. Alcauter concluye que este tipo de subdelegaciones fueron una afrenta para los ayuntamientos y alcaldes ordinarios por perder la preponderancia que les confería el artículo 11, siendo «un freno a su autonomía y a su libertad de acción», dado que la presencia del subdelegado «en su jurisdicción y como presidente del ayuntamiento redujo la relación de los ayuntamientos con las autoridades centrales y con el propio intendente», relegándolos a un segundo plano. ${ }^{9}$ Podemos concluir de este recorrido historiográfico que predomina una visión conflictiva de la relación entre cabildos y subdelegados,

8 Bernal Ruiz, 2019.

9 Alcauter Guzmán, 2012, 58 y 118-119; 2017, 45-55. 
a raíz de la reducción de las facultades de los primeros en el gobierno de los partidos. A esto se suma que no fue excepcional que hubiera subdelegados de cuatro causas en vecindarios de españoles, particularmente en las cabeceras.

La historiografía chilena, por su parte, no ha estudiado las subdelegaciones establecidas por el régimen de intendencias a partir de 1786. Tampoco se han analizado las relaciones entre cabildos y subdelegados. Ha sido objeto de estudio el impacto del nuevo régimen en los cabildos chilenos en la perspectiva de su despertar a fines del siglo XVIII, quedando en claro que la monarquía misma puso en marcha el proceso de restablecimiento de cabildos, que se acentuó y aseguró con el nuevo régimen a través del remate de las varas, la confirmación real de los oficios y la voluntad de los intendentes de restablecerlos. ${ }^{10}$ También ha sido estudiada la relación de los cabildos de Concepción, Santiago y Talca con los intendentes. En este último caso, se analizó la influencia del presidente e intendente de Santiago, Ambrosio Higgins, en la instalación de la familia de la Cruz Bahamonde en la subdelegación y de qué manera uno de sus miembros, Nicolás de la Cruz, consiguió por medio del apoyo de Higgins todo tipo de preeminencias para la villa de Talca y su partido. ${ }^{11}$

\section{El Maule, de corregimiento a subdelegación}

Lo primero que hay que señalar es que la historiografía americana se ha interesado poco por los corregidores en vecindarios de españoles en América colonial, diagnóstico extensible a Chile. La zona pacificada (al norte del río Bio-Bio) fue dividida en corregimientos o provincias a cargo de un corregidor. El despoblamiento del sur de Chile por la guerra de Arauco que se produjo entre fines del siglo XVI y principios del siglo XVII, dejó pocas ciudades en pie, situadas casi todas en la zona pacificada: Santiago, La Serena, Valparaíso, Chillán, Concepción, Castro y, en territorio araucano, la de Valdivia. ${ }^{12}$

El corregimiento del Maule fue establecido por Pedro de Valdivia, el conquistador de Chile. Abarcaba el territorio delimitado por el río Teno y el estero Nilahue por el norte, limitando con el corregimiento de Colchagua, y

10 Enríquez, 2019.

11 Enríquez, 2020b.

12 Lorenzo y Urbina, 1978, 3. 
el río Itata hasta donde empezaba el corregimiento del mismo nombre (en el obispado de Concepción) y el de Chillán por el sur. Desde allí se mantenían fortificados los boquetes cordilleranos por donde se trasladaba el ganado robado desde el otro lado de la cordillera de los Andes.

En 1742, el gobernador presidente José Manso de Velasco, movido por un impulso poblador y en obedecimiento de varias reales cédulas, fundó las villas de Los Ángeles, Cauquenes, Talca, San Fernando, Melipilla, Rancagua, Curicó y Copiapó. Talca se convirtió en cabecera de provincia y de sus villas. Se erigió un cabildo secular pleno y se le concedieron a los vecinos y pobladores mercedes y gracias para establecer estancias, potreros y fincas en las tierras situadas entre los ríos Lontue y Maule. También el rey, por real cédula de 1749, concedió para propios de la villa los derechos de barco y pasaje del río Maule. Talca tenía una ubicación estratégica intermedia entre las ciudades de Santiago y Concepción, zona en la que no había ninguna villa. Se la concibió como un punto de auxilio y contacto especialmente para los tiempos de guerra con los araucanos y también por ser frontera con los indios pehuenches, dado que por su jurisdicción pasaban los caminos reales. En 1769 se desmembró del corregimiento la provincia de Cauquenes, por lo que se redujo su territorio casi a la mitad.

Los corregidores eran nombrados por el rey. Duraban cinco años en sus funciones y eran «autoridades intermedias entre las autoridades locales y el rey, o el virrey y las audiencias», al igual que en Castilla. Presidían los ayuntamientos, calificaban las elecciones y «conservaban facultades que abarcaban las de esos cuerpos políticos en materia de gobierno o se las adjudicaban». ${ }^{13}$ Tuvieron diversas facultades en América según les eran concedidas. Los corregidores chilenos tenían jurisdicción en pueblos de españoles. Eran «justicia mayor, lugarteniente de capitán a guerra y alcalde de minas de la provincia del Maule y sus villas» ${ }^{14}$ en la provincia y las urbes bajo su mandato. Como justicia mayor era un representante de la justicia del rey. Alejandro Agüero explica que, en un distrito en el que había alcaldes ordinarios y magistrados regios, dicha denominación distinguía «al juez regio de las justicias capitulares en el término de la ciudad» $y$, aunque no tenían «un poder jurisdiccional superior», en relación al conocimiento de las causas en primera instancia, «los corregidores (o sus equivalentes) cuando convivían con los alcaldes ordinarios aparecían como autoridades superiores en virtud de su origen regio, de su prestigio profesional y de su mayor

13 Alcauter, 2019.

14 Muñoz Correa y Lacoste, 2015, 223. 
proyección territorial». ${ }^{15}$ José Luis Caño analizó el tema, poco explorado, de si la jurisdicción de los alcaldes ordinarios abarcaba el núcleo poblacional o todo el territorio jurisdiccional, concluyendo que su autoridad y competencia fue ambigua y dependió de cada lugar. ${ }^{16}$ Las causas se tramitaban en el primer juzgado donde eran radicadas, fuera el del corregidor o en el cabildo. En el juzgado del corregidor se podían apelar las sentencias de los jueces del cabildo, solucionar los conflictos entre los cabildantes y apelarse las medidas en materia de gobierno tomadas por el cabildo. ${ }^{17} \mathrm{La}$ Real Audiencia era el tribunal de apelación de todos estos jueces locales. Los corregidores presidían las reuniones del cabildo, aunque no tenían ni voz ni voto, y nombraban tenientes de corregidor para las otras villas o parajes más distantes.

Como lugarteniente de capitán a guerra, era un delegado con «poder y autoridad para ejercer algún ministerio o empleo, con la misma potestad que tiene el que se la comunica», ${ }^{18}$ en este caso el capitán general. Era el encargado de los asuntos militares del corregimiento, dadas sus características de frontera de guerra con los indios pehuenches. Se encargaban, por tanto, de la defensa de su provincia, pudiendo, para ese fin, organizar tropas y campañas de defensa. Tenía fuero militar y, por ello, administraba justicia a quienes gozaban de dicho fuero en primera y segunda instancia. En este último caso, lo hacían con un asesor letrado designado por el gobernador presidente y de estas sentencias se podía recurrir a la junta de guerra de Indias. ${ }^{19}$ Como alcalde de minas tenía jurisdicción judicial y administrativa exclusiva sobre los asuntos mineros, tanto en lo civil como en lo criminal, siendo la Real Audiencia el tribunal de apelación de sus resoluciones. ${ }^{20}$

La instauración de las intendencias suprimió los corregimientos y los corregidores en Chile. Aunque el diagnóstico sobre su corrupto desempeño realizado en la Nueva España y en el Perú (que fue una de las causas del cambio de régimen de gobierno) no era extensible a Chile, dado que no se practicaba el reparto de mercancías ${ }^{21}$ desaparecieron como los de otras

15 Agüero, 2005, 148.

16 Caño, 2009, 41

17 Piña Homs, 1995

18 Diccionario de Autoridades, 1734, s. v. «lugarteniente».

19 Dougnac Rodríguez, 1994, 126-127.

20 Tau Anzoátegui y Martiré, 2005, 116.

21 Expediente formado sobre el nuevo Establecimiento de la Superintendencia General de Real Hacienda, e Intendencias del Reino de Chile, Santiago, 1786, Archivo Nacional de Chile, Santiago (ANCH), Capitanía General, 708, f. 337v. 
zonas americanas. En efecto, los corregidores chilenos recibían un estipendio muy reducido de las visitas a los pueblos indios, del juzgado de minas y del cobro de derechos. Así se reconocía en el Consejo de Indias en 1782 cuando se nombró en el corregimiento de Quillota a un residente en Chile, haciendo mención que los escasos estipendios había provocado que los españoles enviados en el pasado hubieran abandonado el corregimiento por las dificultades para mantenerse. El nombramiento fue hecho «con expresa prohibición de hacer repartimiento y en la misma forma quiere el rey que se expidan todos los demás para ambas américas», ${ }^{22}$ es decir, que la prohibición regía para la Nueva España y el Perú.

\section{Cabildo de Talca y corregidores}

¿Cómo fue la relación de los corregidores del Maule con el cabildo de la villa cabecera? Las actas empiezan en 1759, año en que el cabildo organizó las exequias de la reina Bárbara de Braganza, nombraron a Santa Ana como patrona de la villa, avanzaron en la fábrica de la iglesia matriz y continuaron con la asignación de tierras realengas a los vecinos. Consta en las actas que el corregidor del partido estuvo presente en las elecciones de alcaldes de 1760 y en todas las reuniones de ese año, en el que la principal tarea fue la mensura de tierras realengas y las adjudicaciones y regularizaciones de tierras entre los fundadores de la villa, para lo cual convocaron un cabildo abierto. En relación a la villa, tomaron medidas sobre cómo financiar la ceremonia de jura real y la contención de la peste. En 1761 celebraron las honras fúnebres de la reina María Amalia de Sajonia. El cabildo había encargado la construcción de un barco para navegar el río Maule, cuya ejecución no se había llevado a cabo, por lo que acordaron que otro fabricante lo hiciera. Las reuniones del año 1762 se limitaron a las elecciones habituales y hubo otra en la que se trató el tema del lugar del cabildo en las funciones de tabla. En 1763, luego de las elecciones de alcaldes del mes de enero, aparece copiado el oficio de confirmación de las mismas por el presidente de Chile. En la siguiente reunión no estuvo presente el corregidor, y el cabildo trató temas relativos al bien de los vecinos y adelantamiento de la villa como el uso de la madera de un estero, la visita de pesos, tasas y medidas, cobros de deudas y aprobación de cuentas del procurador. En

22 Consulta de la Cámara de Indias sobre la provisión del corregimiento de Quillota, Madrid, 1782, Archivo General de Indias, Sevilla (AGI), Audiencia de Chile, 331. 
junio de ese año hubo una reunión con un nuevo corregidor que mostró su título al cabildo. El acta fue escrita por el mismo corregidor, señalando que se reunían en su casa por el mal estado y la falta de mobiliario de las salas del cabildo (al igual que las de la cárcel). En consecuencia, proponía que los arriendos del barco del río Maule se aplicaran al arreglo del cabildo, lo que fue aprobado por los capitulares. En la siguiente reunión trataron la situación de los vecinos, a los que se les había otorgado predios para que los edificasen al fundarse la villa sin que eso ocurriera, así como la próxima visita del presidente a Talca. No está el acta de las elecciones de 1764, pero en enero hubo una reunión en la que el procurador de la villa presentó las cuentas, se leyó un informe del juez agrimensor sobre tierras vacas y aprobaron que el archivo del escribano que había en la villa se custodiase en el cabildo. A propuesta del corregidor se aprobó llamar a un cabildo abierto para tratar el tema de la falta de médico y hospital en la villa, así como el estar vigilantes para denunciar la presencia de indios en tierras de un vecino. En la siguiente reunión se leyó un decreto del superior gobierno relativo a los arrendamientos del barco.

En otra reunión del cabildo del mismo año, el procurador general de las villas del corregimiento asistió para tratar temas relativos al esplendor y lustre de las mismas. Acordaron que se notificara a los vecinos que no habitaban sus predios, en los que además no había fábrica, que lo hicieran o vendieran; se ejecutara la concesión de chacras a los fundadores de las villas mandadas por reales cédulas; que a los reos destinados a obras públicas en el corregimiento no se les cargara con el carcelaje y que la mantención de la cárcel corriera a cargo del aguacil mayor. La reunión siguiente fue nuevamente en casa del corregidor y se analizó la propuesta del presidente de nombrar un fiel ejecutor del partido y sus tres villas, lo que fue rechazado por la cortedad de los ingresos de los vecinos para poder gravarlos con un nuevo salario y que quedara en manos de los capitulares de ese ayuntamiento el cumplimiento de ese oficio.

En las elecciones del 1 de enero de 1765, el corregidor hizo leer las ordenanzas de erección de la villa, en las que se ordenaba que el capitular que no viviese en ella no podía tener voz ni voto en el ayuntamiento, por lo que mandó que el depositario y el alférez real se retiraran de la sala capitular y se procedió a la elección, quedando expresamente escrito en el acta que la recepción de los elegidos se produciría después de la confirmación por parte del presidente. La confirmación no llegó, pero sí un decreto del presidente que declaraba nulas las elecciones y extensible a todos los 
capitulares. En la siguiente reunión, el corregidor les leyó el decreto, les pidió que entregaran sus bastones sin queja y salieran. A continuación, recibió a los alcaldes nombrados por el presidente. De esta manera se extinguió el cabildo por orden del presidente Guill y Gonzaga. ${ }^{23}$

¿Cómo fue esta primera etapa de vida capitular? El cabildo se estableció y trató principalmente temas relativos a la villa. Los corregidores presidieron las reuniones del cabildo. Queda claro que desde el superior gobierno había voluntad de que las fundaciones se mantuvieran, de ahí la existencia de un procurador general activo y la propuesta de que hubiera un fiel ejecutor para las tres villas, la concesión de propios y la vigilancia de su cobro y uso, y el cumplimiento de la ordenanza de erección de la villa que se aplicó para extinguir el cabildo. Es evidente el control de la vida capitular desde el superior gobierno de Chile a través de los corregidores.

El año 1766 principia con un acta en la que el corregidor menciona la extinción del año anterior y un decreto del presidente para que nombrara alcaldes que lo ayudaran en la administración de justicia. El corregidor explica que con anticipación hizo saber al presidente cuales eran los sujetos idóneos y que este los había nombrado junto a los otros oficios del cabildo. Lo mismo se repitió en 1768. La siguiente acta es del 1 de enero de 1771, en la que un nuevo corregidor deja constancia de los nombramientos de cabildantes hechos por el presidente de Chile, a quien se pide en 1775 el poder pasear el estandarte real el día de la Virgen de la Merced. Continúan las actas de tomas de posesión de dos corregidores en 1772 y 1773, y los nombramientos de capitulares hechos por el presidente chileno en ambos años. El año de 1774 también se inicia con la toma de posesión de los cabildantes nombrados por el presidente a propuesta del corregidor. A fines de 1775, el cabildo recibió al regidor decano perpetuo y se leyó un informe del superintendente de la villa relativo a la incomunicación en su interior por no haber puentes sobre el estero que la cruzaba, por lo que proponía construir un tajamar y solicitaba los recursos para ello, que le fueron concedidos. ${ }^{24}$

Terminaba así una segunda etapa de vida del cabildo que se inició con su suspensión y el nombramiento de alcaldes y oficios por parte del presidente de Chile a propuesta del corregidor. Por medio de un intercambio epistolar entre Julián de Arriaga, secretario de Marina e Indias, con el presidente Agustín de Jáuregui, del 1 de diciembre de 1773, conocemos cómo finalizó esta etapa. Jáuregui dio cuenta al secretario que había recibido una

23 Muñoz Correa y Lacoste, 2015, 170-193.

24 Ibidem, 193-203. 
carta del 14 de junio en la que le pedía que cooperara para que se restablecieran los oficios concejiles en Talca por medio de la venta y remate de los mismos conforme a las leyes, comprometiéndose a ejecutarlo. Y agrega que iba a procurar que se restablecieran los otros cabildos suprimidos en Chile por similares causas para el aumento de las ciudades y villas y la efectividad de las disposiciones reales. ${ }^{25}$

De esta manera, un presidente, por orden de Madrid, restableció lo que otro había suspendido. Así se evidencia en la tercera etapa de la vida del cabildo, que se inició con las elecciones de 1776, las que tuvieron la particularidad de que se realizaran en ausencia tanto del corregidor como del escribano, que era miembro del cuerpo. Este último había sido citado para que estuviera presente, pero no asistió por acompañar al corregidor en otra tarea. En virtud de dicho desobedecimiento, se acordó que, en adelante, debía pedir permiso al cuerpo para ausentarse. Las actas dan cuenta de un conflicto entre el cabildo y el corregidor a raíz de un auto formado por este prohibiendo al alférez real el uso de bastón si no se hallaba de subalterno, y a los regidores y alcaldes entrar con espada a la sala capitular o donde se reunieran. Por ello citaron al corregidor para que declarara si el auto provenía de orden superior, a lo que contestó que emanaba de su autoridad. A continuación, se copia un oficio del juez pesquisidor nombrado por el presidente de Chile por los excesos del corregidor de la provincia del Maule, que se seguían en la Real Audiencia. En agosto, el cabildo se reunió con el juez, quien les comunicó que había sentenciado prisión y embargo contra el corregidor. Señalaba también que el fiscal le había pedido que consultara al cabildo sobre el sujeto a nombrar como corregidor subrogante en caso de suspensión del propietario. Se acordó el nombramiento de un antiguo corregidor para que no quedara acéfala la provincia.

En 1777 solo hay un acta del mes de diciembre en la que se acuerda convocar un cabildo abierto para organizar la defensa de la provincia ante una posible rebelión de los indios que les era comunicada por el maestre de campo general del reino. Este es el único acuerdo del cabildo en el que lo vemos actuar como cabecera de corregimiento o provincia. En enero de 1778, las actas dan cuenta de una nueva reunión de planificación de defensa de la villa ante una posible invasión de los indios y la posibilidad de pedir una contribución de los vecinos. En otra reunión trataron sobre los propios de la villa y la necesidad de recaudar lo adeudado por ese concepto para

25 Carta de Agustín de Jáuregui, presidente de Chile, a Julián de Arriaga, secretario de Marina e Indias, Santiago, 1 de diciembre de 1773, AGI, Audiencia de Chile, 189. 
refaccionar obras públicas. De 1780 a 1782 solo se encuentra el acta de elección de alcaldes. En 1783 consta la llegada de un nuevo corregidor, mientras que en 1784 solo hay un acta de elección de alcaldes. Un año más tarde, 1785, además de la elección del 1 de enero, hay otras actas en las que se acuerda la refacción de las salas del cabildo, la cárcel y una acequia; se fija el precio del pasaje por los ríos; se aprueba que los remates de especies de abasto que se pregonaran fueran por cuatro años, y se determina el lugar de almacenaje de la cal y el precio de la fanega. Estos acuerdos apuntaban al aumento de los propios de la villa. Así culminaba esta tercera etapa, que comenzó con un golpe de fuerza del cabildo contra el corregidor, que fue destituido, con la intervención del superior gobierno y con el nombramiento de un corregidor interino consensuado con el cabildo. Recomenzaron a partir de entonces las elecciones del 1 de enero de cada año. Los otros temas que se trataron fueron los relativos a la recaudación de propios y su destino en la villa.

El cabildo de Talca, por tanto, fue cabecera de corregimiento entre 1759 y 1786 . Quedan huellas en las actas de un control fuerte de su funcionamiento y su misma existencia desde el superior gobierno a través de los corregidores. Dicho control se llevó a cabo mucho más allá de la confirmación de las elecciones: había oficios provinciales sobre las villas, los corregidores estaban presentes en las reuniones del cabildo y no permitieron que este cuerpo no respetara las cédulas de erección de la población, finalmente, el cabildo fue suspendido y restablecido.

\section{Las subdelegaciones en Chile}

Como hemos visto, el diagnóstico de la necesidad de cambio de régimen de gobierno no encajaba con la realidad chilena, justificándose por ser voluntad real el «uniformar el Gobierno de estos Reinos por medio de las Intendencias que en todo el deben establecerse». ${ }^{26}$ De hecho, Teodoro de Croix, virrey del Perú, era de la opinión de que con la implantación del nuevo régimen en Chile sería

muy corta la variación, o alteración sensible que por ahora se note en su Gobierno como que se continúan en este las mismas personas que hasta ahora le han tenido,

26 Carta del visitador Jorge Escobedo a Ambrosio de Benavides, presidente de Chile, Lima, 6 de septiembre de 1784, ANCH, Fondo Morla Vicuña, vol. 7, f. 499. 
aunque con distintos nombres, o Títulos, sin otra diferencia, que las de darles nuevas reglas y más amplias facultades, para que con mayor facilidad puedan proporcionar en todos los ramos, o causas el mejor arreglo, y los demás laudables objetos a que se dirige el establecimiento. ${ }^{27}$

Sin embargo, durante el proceso de discusión sobre cómo establecer las intendencias en Chile, se debatió mucho sobre las subdelegaciones. La ausencia de pueblos de indios implicaba que no iba a haber subdelegaciones de cuatro causas - sólo de dos- en los vecindarios de españoles. Sin embargo, cuando la Junta Superior de Real Hacienda resolvió cómo establecer las subdelegaciones, decidió que todos los subdelegados de vecindarios de españoles fueran de cuatro causas con jurisdicción en todo el partido, aplicándose el mismo criterio que en el virreinato del Perú. ${ }^{28}$

Respecto a los corregidores, el cambio de autoridades implicó mayores facultades en todas las causas de gobierno. José Luis Alcauter explica que los corregidores no eran superiores a los alcaldes en las provincias, sino que el rango de su cargo se determinaba por la importancia de la ciudad. Sin embargo, eso cambió a partir de la implantación de las intendencias, «pues ahora sí el intendente corregidor sería el superior de todos los jueces territoriales, llamados subdelegados», dado que «los intendentes tendrían el cargo de corregidor junto con el de intendente». ${ }^{29}$ Además, estos últimos, por tener la jurisdicción de las cuatro causas en sus provincias, tuvieron más facultades que los corregidores, que sólo eran justicias mayores. La jurisdicción real de los corregimientos recaía en los intendentes sin que se modificara «la que en los pueblos de españoles corresponde a sus alcaldes ordinarios». Los intendentes tenían la tarea de nombrar en los pueblos jueces subdelegados que no tuvieran repartimientos con el fin de dejar que los indios y las castas tuvieran «libertad para comerciar». Como sus subalternos, los subdelegados tenían también las cuatro causas en subordinación a los intendentes, según se situaran en pueblos de indios o de españoles.

Los intendentes tenían la facultad de confirmar las elecciones de los alcaldes de los cabildos (artículo 8) y de presidir las reuniones de los cabildantes en las ciudades cabeceras de intendencia. La ordenanza establecía

27 Expediente formado sobre el nuevo establecimiento de la Superintendencia General de Real Hacienda, e Intendencias del Reino de Chile, Santiago, 1786, ANCH, Capitanía General, 708, f. $349 \mathrm{v}$.

28 Ibidem, f. 370.

29 Alcauter, 2019, 27. 
una Junta Superior de Real Hacienda para supervisar la implantación del nuevo régimen, la que tenía a su cargo la «inspección y derecho privativo» sobre los «propios y arbitrios de pueblos de españoles», para lo cual el secretario actuaría como contador general. Los intendentes debían pedir a los pueblos que informaran sobre los propios y arbitrios, además de redactar un reglamento sobre la administración de dichos ingresos a remitir a la Junta Superior, la que debía solicitar la real confirmación. También en cada pueblo de españoles se debía establecer una Junta Municipal para la administración de los propios y arbitrios.

El artículo 25 detalla la información que el intendente debía pedir a los pueblos, villas y lugares de españoles sobre sus propios y arbitrios, su existencia, el origen de los mismos, las cargas perpetuas y los gastos extraordinarios. El artículo 26 precisa que el informe lo debían enviar los alcaldes ordinarios y los subdelegados. En el caso de concesiones reales, se debía incluir la información sobre el destino de los fondos, si subsistía la razón de la misma y si se había terminado el período de la concesión y sus prórrogas. Toda la información debía de enviarse a la Junta Superior. El artículo 27 establecía que, con esos testimonios, el intendente debía «formar un reglamento interino para los propios y arbitrios» de los pueblos, que debía ser evaluado por la Junta Superior y enviado por la vía reservada para la confirmación del rey. Los artículos siguientes reglamentaban el funcionamiento de una Junta Municipal que tenía a su cargo la administración de los propios y arbitrios. Debía estar compuesta por el alcalde de primer voto, dos regidores y el procurador general, quienes debían designar anualmente un mayordomo. Respecto a la causa de policía o gobierno, intendentes y subdelegados debían elaborar mapas para conocer los terrenos de la intendencia, su calidad y conocer los medios para mejorarlos. El articulo 55 establecía cómo corregir y castigar a los ociosos y mal entretenidos, y el destino aplicable a vagos y mendigos de profesión estaba contenido en el artículo 56. El artículo 57 establecía los medios para el fomento en las castas de la agricultura (sobre todo el cultivo del cáñamo y el lino) y cómo se les podían repartir tierras realengas. El artículo 59 les encomendaba el fomento de la industria, la minería y el comercio, y el 60 el reparo y conservación de los caminos y los puentes. Finalmente, el artículo 65 pedía la reparación de los edificios públicos, su ornato y limpieza.

Los subdelegados de intendente (artículo 9) se nombraban para los pueblos de indios que fueran cabecera de partido y en las ciudades o villas en las que hubiera habido corregidor o teniente de gobernador, con las 
facultades de las cuatro causas. Mientras que en las ciudades y villas de numeroso vecindario y en las cabeceras de los gobiernos políticos y militares había subdelegados de lo contencioso de guerra y hacienda (artículo 73). En estos casos, quedaban en los cabildos las causas de justicia y policía que habían estado en manos de los corregidores. Los subdelegados de dos causas no tenían distinción de asiento en los cabildos, mientras que los de cuatro causas los presidían. Respecto a los sueldos de los subdelegados, el artículo 117 señalaba que, del total del $4 \%$ del tributo de indios que el subdelegado entregaba a la tesorería, le correspondía el $3 \%$, quedando el $1 \%$ para los cobradores. ${ }^{30}$

Por tanto, los subdelegados «en los cabildos que no eran cabecera de intendencia, en los cuales el gobernador no ejercía las cuatro causas, cobraban más autoridad». ${ }^{31}$ De manera que, según la ordenanza, debía haber dos clases de subdelegados, los de dos causas se situaban en las villas que no eran capitales de intendencia, y los de las cuatro causas en villas de «numeroso vecindario» que, según Edberto Acevedo, se interpretó como ciudades de blancos. ${ }^{32}$ No había en la ordenanza ningún mecanismo de nombramiento de subdelegados, aunque en el artículo 9 se decía que las designaciones eran tarea de los intendentes y por el «tiempo de su voluntad». Sin embargo, una real cédula de 1788 determinó que los intendentes debían dar cuenta de los nombramientos a virreyes y gobernadores explicando sus cualidades para el empleo. Otra real cédula de 1792 modificó esta facultad dado el enorme poder que les otorgaba y estableció que los subdelegados duraran cinco años en sus puestos, que los intendentes los propusieran por medio de ternas a virreyes y gobernadores, y que requerían la confirmación real.

\section{El cabildo de Talca en la subdelegación del Maule}

¿Qué implicó para el cabildo de la villa de Talca el cambio de régimen de gobierno en 1786? En aquel momento estaba compuesto por los dos alcaldes ordinarios, alférez real, regidor decano, depositario general, procurador y escribano. Como cabecera de partido, la villa fue el asiento del subdelegado. No se perciben en las actas del cabildo enfrentamientos

30 Real Ordenanza para el establecimiento e instrucción de intendentes de ejército y provincia en el virreinato de Buenos Aires, año 1782, ANCH, Fondo Varios, vol. 1028, 1786, 4-57.

31 Comadrán Ruiz, 1995, 40.

32 Acevedo, 1992, 108. 
con el intendente o los subdelegados, sino aceptación de sus disposiciones y colaboración. El nuevo régimen encontró al cabildo en la resolución de un problema de toma de tierras públicas que se había producido durante la época en que fue suspendido por el presidente Antonio Guill y Gonzaga. Por ello, sus miembros acordaron que el agrimensor del partido volviera a mensurar la villa y se solicitara con ese fin la escritura de donación de terrenos a la orden agustina que había permitido la fundación. Otra reunión tuvo por objeto nombrar un nuevo procurador general por muerte de quien lo era. ${ }^{33}$ Por último, el 5 de julio trataron el tema de una representación verbal hecha por el subastador del ramo de la concha de la provincia, que quería establecer una casa y oficina junto a la quema de la concha lindante con la parte del mar, cuyos realengos pertenecían al uso común. Resolvieron al respecto que, por ser una actividad tan importante para la provincia, se estableciera y se comunicara a los dueños de las estancias cercanas que no podían impedir u obstaculizar el establecimiento de dicha fábrica. De la concha quemada se obtenía una argamasa que se usaba en las construcciones.

La reunión del cabildo del 26 de agosto de 1786 estuvo presidida por primera vez por un subdelegado de intendente y justicia mayor, que era Juan de Salcedo. La fórmula no implica, como hemos explicado, que el subdelegado fuera justicia mayor del partido, sino que se refiere a las facultades del intendente. Los temas de la vida rutinaria del cabildo cambiaron. Se acordó realizar un paseo del estandarte real en el que debían participar todos los vecinos y las milicias. Esta ceremonia no se había podido hacer en el pasado por la falta de propios, pero «atendiendo al bien público, honor a la república y adelantamiento del vecindario, amor de su soberano como fiel vasallo, se prometía contribuir con todo lo necesario a la celebridad del día». Debido a la escasez de propios, se acordó financiar la ceremonia con las multas de quienes no quisieran asistir. ${ }^{34}$ Pero, cuál era la verdadera razón de que se iniciara la implantación del nuevo régimen de gobierno con el paseo del estandarte real acordado en el cabildo. En primer lugar, hay que recordar que escenificaba el paso del monarca por la ciudad. El estandarte, como insignia del poder real, portaba un capital simbólico exclusivo de la autoridad del rey que se hacía presente. También simbolizaba la presencia del estado y un elemento de integración política, así como la toma de posesión de un territorio y la soberanía real sobre el mismo. ${ }^{35}$ Varias reales

33 Muñoz Correa y Lacoste, 2015, 222-223.

34 Ibidem, 2015, 223-226.

35 Cárdenas Gutiérrez, 2002, 200-203. 
cédulas desde el gobierno de Carlos V ordenaban sacar el estandarte por las ciudades llevado por un regidor, función a la que debían asistir todas las autoridades reales. La decisión de que se paseara el estandarte puede tener varios significados. En primer lugar, que las nuevas autoridades instaladas por el cambio de régimen de gobierno iniciaban el mismo expresando su sumisión al rey. En segundo lugar, era una decisión tomada por el cabildo en el primer acuerdo en el que participaba el subdelegado, lo que podemos entender como un mensaje de aceptación de la nueva autoridad, de subordinación y de unidad del cabildo con el subdelegado. Finalmente, también expresaba la presencia de la autoridad real en la ciudad y el partido.

La siguiente reunión del año trató sobre el abastecimiento de cal para el curtido de cueros, que siempre escaseaba porque estaba mal proveído pese a ser un producto estancado. Por eso resolvieron que se aplicaran «los capítulos de intendencias número veinticinco, veintiséis y cuarenta y dos» para que se aboliera el estanco de la cal por «perjudicial al común». ${ }^{36}$ ¿De qué trataban estos artículos? Por el artículo 25, los intendentes debían pedir informes a los pueblos de sus propios y arbitrios o de los bienes de comunidad; por el artículo 26, los intendentes podían determinar la extinción o subsistencia de los arbitrios y, finalmente, por el 42, se le permitía a la Junta Superior de Real Hacienda que resolviera sobre la continuidad de arbitrios que hubieran expirado y los que habían sido establecidos por los pueblos. ${ }^{37}$ También los cabildantes dejaron constancia que, respecto al artículo 31 (remate de los propios y abastos a cargo de las Juntas Municipales), no había habido interesados en el remate. Finalmente, abordaron la situación de la concha marina, uno de los propios de la villa, estatuido por uno de los presidentes de Chile, que había sido subastado y rematado. El subastador había pagado las fianzas habituales, pero se le estaban cobrando ciertos perjuicios ajenos al remate, por lo que resolvieron poner la situación en consideración del presidente y del fisco, dado que se negaba a pagarlos, posibilidad incluida en la real ordenanza. ${ }^{38}$ En este caso, queda claro que el cabildo recurrió al intendente para resolver problemas relacionados con los propios de la villa en una clara subordinación a la nueva autoridad, que actuaba como árbitro.

36 Muñoz Correa y Lacoste, 2015, 227.

37 Real Ordenanza para el establecimiento e instrucción de intendentes de ejército y provincia en el virreinato de Buenos Aires, año 1782, ANCH, Fondo Varios, vol. 1028, 1786, 28, 29 y 44.

38 Ibidem, 34. Muñoz Correa y Lacoste, 2015, 227. 
La última reunión del año analizó el tema del desmembramiento de un nuevo partido al que aspiraban los vecinos de la villa de Curicó, lo que la convertiría en cabecera. El acta resume una representación del cabildo al superior gobierno. Se inicia con la historia del corregimiento del Maule y hace referencia al momento en que se desmembró en 1769 del corregimiento de Cauquenes, quitándole la mitad de su territorio, «sin que por ello haya resultado adelantamiento alguno para dicha provincia, haciendo agravio a los de esta». Señalan que, aunque el superior gobierno había seguido los procedimientos acostumbrados, es decir, que había pedido el informe de rigor al corregidor, este respondió positivamente porque quería acomodar allí a un pariente suyo, consiguiéndolo. Por eso, consideraban que el nuevo desmembramiento limitaba el territorio original a un tercio, perdiendo la jurisdicción de dos villas y los propios, que proporcionaban gran cantidad de concha marina que pasaban a la nueva subdelegación. Se reducían también los ingresos por los derechos de paso por el río Mataquito y por el uso de las canchas de juego de bolas. Los vecinos tendrían una doble jurisdicción por estar sus haciendas situadas en el nuevo partido y sus casas en Talca. Además, faltaría gente para el resguardo de los boquetes cordilleranos y los milicianos estarían más exigidos, dado que deberían cubrir un piquete diario para la vigilancia de las cárceles, el auxilio de la justicia y el traslado de los delincuentes a los presidios.

Señalaban que los vecinos de Curicó aspiraban al adelantamiento de la villa y creían que, si uno de ellos o alguien de otro lado era nombrado subdelegado, se engrandecerían. Argumentaban que no era el engrandecimiento de una villa la razón para adquirir «facultades mayores soberanas», sino la situación comercial. Talca, situada a 80 leguas de Santiago y de Concepción, era un lugar de comercio al que acudía mucha gente y tenía fama de ser mayor que el resto de las villas nombradas. Opinaban que, si Curicó quería engrandecerse, las autoridades debían obligar a que se avecindaran en ella setenta vecinos que vivían en las inmediaciones, lo que había sido una constante indicación del superior gobierno, para que gozaran de la vida política y la felicidad. Además, debían labrar las tierras «y no esperar subdelegado para que los haga trabajar, que esto solo sería visto de gente bárbara e inculta y no de aquellas inmediaciones que la conocemos por civilizada».

Dado que la distancia entre Talca y Curicó era de 20 leguas, los talquinos señalaban que se dificultaría mucho acudir a un juzgado allá, por lo que creían que sería mejor que en el cabildo de Talca hubiera un alcalde 


\section{LUCRECIA ENRÍQUEZ}

ordinario, con voz y voto en el ayuntamiento, ante quien se pudieran seguir los juicios ordinarios. Pedían que hubiera en Curicó un escribano, un procurador síndico que cuidara el adelantamiento de la población y un alguacil a cargo de la cárcel. También que el alcalde que se eligiera fuera un vecino residente en la villa, que revisara las cuentas del procurador y actuara con su acuerdo en las obras públicas. Por todo ello, el cabildo pedía al gobernador presidente y a la Junta Superior de Real Hacienda no sólo que no fuera desmembrada la provincia, sino que se le agregara nuevamente el partido de Cauquenes y su villa. Esta representación fue firmada el 22 de noviembre de 1786 por todos los miembros del cabildo. ${ }^{39}$

En este caso, el cabildo de Talca argumentó como cuerpo y cabeza del partido ante la posibilidad del desmembramiento, incluso pidiendo la presencia de un alcalde en su corporación para atender las demandas de los vecinos con haciendas que cambiarían de jurisdicción. Mostraron las nulas ventajas que había traído a la villa de Cauquenes el convertirse en cabeza de corregimiento en el pasado. Pero la decisión estaba tomada. En efecto, la Superintendencia de Real Hacienda consultó al respecto a la Junta Superior de Real Hacienda de Chile, la que informó que estaba ya aprobada la erección de la subdelegación de Curicó. ${ }^{40}$

El año de 1787 se inició con la elección de alcaldes. En febrero se reunió el cabildo para tomar conocimiento de un oficio del presidente del 21 de noviembre de 1786 otorgando permiso para la continuidad de los arrendamientos de barco del río Maule en el que, además, se solicita al subdelegado y al cabildo que informaran sobre las obras públicas necesarias, costos y si convenía sacarlas a remate o que se ejecutaran por medio de un vecino. En la reunión acordaron que los edificios más urgentes para refaccionar eran: la cárcel, las salas de cabildo, acequia y cuatro puentes en las cuatro calles por las que pasaba un estero.

La siguiente reunión fue la de elección de alcaldes en 1788, que se hizo de la manera acostumbrada y en febrero nombraron procurador y alcaldes de la hermandad. No registran las actas otra reunión ese año. 1789 se inició con la elección de alcaldes ordinarios. Consigna el acta que se hizo en conformidad a la recomendación del presidente interino, Tomás Álvarez de Acevedo, que había pedido que se tuviera en cuenta en las elecciones al alcalde del año anterior, el que fue ratificado como alcalde de segundo

39 Muñoz Correa y Lacoste, 2015, 229-231.

40 Copia del capítulo 5 de la consulta hecha por la Superintendencia a la Junta Superior de Real Hacienda, Santiago, 1787, ANCH, Capitanía General, 549, f. 155. 
voto. Una urgencia provocó una reunión el día 3 de enero: la presencia en las inmediaciones de la villa de enfermos de viruela, razón por la cual era necesario tomar medidas. Decidieron que fueran llevados en carretas al lugar que se había usado de hospital con anterioridad, donde quedarían al cuidado de dos personas y dos guardias, que debían cuidar de que no saliera nadie sin haber cumplido la cuarentena. Para el cuidado y remedios de los enfermeros, acordaron sacar de los propios de la villa 50 pesos y, una vez gastado, se costearían los nuevos gastos por medio de un arbitrio obtenido de los vecinos y hacendados de las doctrinas cercanas. En abril se celebró la última reunión en la que se eligieron los alcaldes de la Santa Hermandad para las doctrinas, reunión que fue presidida por el nuevo subdelegado de intendencia y teniente de capitán general de partido y sus villas, el regidor perpetuo decano Vicente de la Cruz. La reunión del 1 de enero de 1790 fue presidida por el subdelegado, se eligieron los nuevos alcaldes y se resolvió que un asunto (no detallado) presentado ante el cabildo se trasladara al subdelegado para que lo resolviera en justicia. ${ }^{41}$

Debía el intendente y, por tanto, su subdelegado, preocuparse por el buen estado de los edificios públicos. Es visible en las actas del cabildo cómo se impulsa desde la intendencia que se apliquen los propios de la villa en esos arreglos y cómo se toman las medidas para que los hubiera. También en la intervención del intendente en las elecciones de alcalde notamos una continuidad de anteriores injerencias de los tiempos de los corregidores. Álvarez de Acevedo también intervino en la elección de alcaldes del cabildo de Santiago, lo que le valió una denuncia ante el Consejo de Indias y una condena a su actuación..$^{42}$ Además, las decisiones sobre la contención de la viruela en el partido y su financiamiento fueron tomadas por el cabildo de Talca.

La reunión de julio se desarrolló en base a la lectura de una real provisión enviada por la Real Audiencia, que contenía la real cédula dada en Aranjuez el 3 de mayo de 1789, y los acuerdos para su cumplimiento. Trataba sobre el vestuario, alimento y trabajo de los esclavos. En septiembre, el subdelegado propuso tratar el tema de la alimentación de los presos de la cárcel. La costumbre era que los vecinos los alimentaran uno por cada día del mes. Sin embargo, había días que no recibían alimento porque algunos vecinos se negaban, por lo que había sublevaciones e intentos de asesinato.

41 Muñoz Correa y Lacoste, 2015, 232-238.

42 Enríquez, 2020a, 49-52. 
El subdelegado propuso a los cabildantes que obligaran a los vecinos que se negaban a hacerlo, lo que fue acordado.

No está el acta de la elección de alcaldes de 1791. La reunión de mayo estuvo presidida por el alcalde de primer voto que hizo de subdelegado. Leyeron un oficio del subdelegado propietario al presidente y las resoluciones posteriores. Aunque el tema de este intercambio no está claro, parece deberse a un conflicto en el cabildo por el procurador, a quien se oponía el alférez real (hermano del subdelegado) y apoyaban el resto de los cabildantes. El tema se zanjó con la ratificación del electo cuando se retiró el alférez de la votación. ${ }^{43}$

Este año el cabildo pidió al presidente Higgins que intercediera ante el rey para obtener el título de ciudad por medio de un oficio en el que exponían sus méritos y servicios. Destacaban especialmente la contención de los indios araucanos y pehuenches, conservando el territorio para la corona y la muerte del cacique Lautaro en el río Mataquito. El presidente inició un expediente al respecto, visitó la villa y recomendó a la cámara de Indias la concesión del título. ${ }^{44} \mathrm{El}$ fiscal del Consejo y la Contaduría Mayor lo justificaron por ser Talca cabecera de partido. Finalmente, el consejo indiano y el monarca apoyaron la concesión a Talca del título honorífico de ciudad:

Lo $1 .^{\circ}$ para acabar de reconcentrar en ella muchos habitantes del partido, que desdeñaban el nombre de villa: Lo $2 .^{\circ}$ porque estando situada en el centro precisamente de las 150 leguas que median entre Santiago y la Concepción, su situación misma había fomentado el establecimiento de escuelas públicas de primeras letras y de latinidad, donde concurren los jóvenes de los partidos inmediatos, que no pueden hacerlo a las dos capitales referidas, cuya enseñanza es propia de pueblos principales, según las leyes; y lo $3 .^{\circ}$ porque de este modo podría formalizarse con más brevedad la nueva villa, que había delineado a 12 leguas de distancia de Talca en la embocadura del rio Maule con el objeto de fomentar la construcción de barcos para transportar por barco hasta Valparaíso los granos, cecinas y madera, que salen de ese puerto para Lima, ahorrando los crecidos gastos que se hacen en el día en el transporte por tierra. ${ }^{45}$

En este proceso, queda claro que el cabildo actuó como cabecera impulsando una medida que iba en la línea de asentar a los vecinos en la villa, fomentar la educación en el partido y atraer jóvenes de otros, todo lo cual repercutiría en un desarrollo favorable a la fundación de una nueva villa y el

43 Muñoz Correa y Lacoste, 2015, 240.

44 «El cabildo y Ayuntamiento de la villa de San Agustín de Talca...», 1927.

45 Extractos de las consultas de 13 de enero y de 5 de octubre, Madrid, 1796, AGI, Audiencia de Chile, 172B. 
desarrollo del comercio. Pero también desde el Consejo de Indias se apoyó la medida para darle a Talca la calidad de villa cabecera.

La elección de alcaldes de 1792 fue objetada por el presidente, ya que se eligió al administrador de la renta del tabaco como alcalde de segundo voto, ${ }^{46}$ por lo que el 23 de enero se eligió a otra persona para esa vara y en febrero se nombraron los alcaldes de la Santa Hermandad para las doctrinas. La siguiente acta corresponde a la elección de alcaldes de 1 de enero de 1793 y de alcaldes de la Hermandad para las doctrinas. En abril volvieron a reunirse los capitulares y trataron el tema del remate de la propiedad de un vecino para saldar una deuda con el ayuntamiento. Ante la falta de compradores resolvieron usar la casa para establecer una «escuela para el común» y a futuro un seminario para educar jóvenes. En agosto, el tema fue la dispensa de la Silla Apostólica de comer carne durante cuatro días de la semana durante la cuaresma. Además de comunicarlo, el rey había concedido que la limosna proveniente de la venta de esa bula se usara con fines benéficos y, para ello, le había pedido al presidente que informara de las necesidades públicas del territorio. El cabildo respondió que era un hospital para los pobres y reos encarcelados.

El año de 1794 se inició con las elecciones de alcaldes ordinarios y en febrero se hizo el nombramiento de los alcaldes de la Santa Hermandad para las doctrinas del partido. En la reunión de agosto acordaron trasladar la fecha del paseo del estandarte real del 28 de agosto, día de san Agustín, patrón de la ciudad, que coincidía con la temporada de lluvias, por lo que no se realizaba. Acordaron que serían los días 28 y 29 de octubre en la iglesia matriz, llevando en procesión la imagen del santo. ${ }^{47}$

Tres temas nos parecen destacables de todo lo registrado en actas. En primer lugar, la comunicación del superior gobierno con el cabildo, al que consulta como cabeza del partido el envío de reales cédulas para su aplicación, y el diálogo entablado por medio de consultas sobre las necesidades públicas para la asignación de los fondos de cruzada. En segundo lugar, el control de las elecciones ante la acumulación de cargos en una persona y, a la vez, la resolución de los conflictos por los oficios al interior del cuerpo capitular. Por último, la decisión de establecer una escuela con el dinero de un remate y, en el futuro, un seminario de jóvenes. Sin duda, ambos acuerdos apuntaban no solo a la villa, sino también al partido y a la formación de sus habitantes.

46 Elección de alcaldes del Partido de Maule, año de 1792, ANCH, Capitanía General, 1020, f. 81.

47 Muñoz Correa y Lacoste, 2015, 239-245. 
Las actas de 1795 corresponden a las elecciones de alcaldes del 1 de enero. En 1796 sólo se renovaron, en el día citado, el alcalde de segundo voto y el procurador. En febrero, los cabildantes se reunieron para resolver cómo obedecer un superior decreto de 23 de octubre de 1795 relativo a los sueldos de los subdelegados. Se señalaba también que los ingresos por tributos eran insuficientes y no había un ramo de la real hacienda para asignarles. Por tanto, los subdelegados debían reunirse con los cabildos de las cabeceras para resolver con qué fondos y arbitrios podían pagar los 600 pesos correspondientes a los sueldos sin perjuicio público. Los cabildantes de Talca resolvieron que el sueldo provendría de arriendos de tierras y, como la suma era de 150 pesos, sería una dotación fija y que a futuro se podría completar con arbitrios. Esta era la única solución sin perjudicar al público, si bien se le podrían sumar los tributos de un pueblo de indios si el subdelegado se los cobraba. ${ }^{48}$

A partir de la instalación de las intendencias, se demarcaron las diputaciones judiciales encargadas a un juez diputado que en parte suplía las tareas de los antiguos tenientes de corregidor y sumaba la facultad de perseguir a los vagos y mal entretenidos. ${ }^{49}$ En el cabildo de Talca, las diputaciones judiciales aparecen mencionadas en las actas recién en 1796. Recordemos que estos alcaldes eran la policía rural encargada de los delitos que se cometían en despoblados, no en las ciudades. Su coexistencia demuestra que los jueces diputados no reemplazaron a esta policía rural y que el cabildo mantuvo la prerrogativa del nombramiento de alcaldes en el partido mientras que los jueces diputados eran nombrados por el intendente. Desde 1796, las diputaciones aparecen demarcadas dentro de las antiguas doctrinas en esta singular agregación de jurisdicciones que se construían sobre la primera que había sentado jurisdicción. También es de sumo interés la información sobre los salarios de los subdelegados, dado que la real ordenanza establecía que se obtendrían de un porcentaje del tributo que pagaban los indios, el que no recaudaban los subdelegados chilenos porque los indios no los pagaban. De esta manera, se aclara que se cargaron los sueldos de los subdelegados a los ingresos del cabildo de la cabecera.

La última reunión fue en noviembre y, en ella, los cabildantes acordaron publicar una real cédula que concedía a la villa de Talca el título de ciudad, acompañando la noticia con un programa de diversiones públicas y el paseo del estandarte real. El acontecimiento se difundió por medio de

48 Muñoz Correa y Lacoste, 2015, 246-247.

49 Enríquez, 2016. 
un bando que anunciaba a los vecinos los festejos que se celebrarían los días 23 y 24 de diciembre, la iluminación de la plaza pública a costa de los propios de la ciudad y la petición a los vecinos de que engalanasen sus casas, las revocaran y blanquearan. Habría fuegos artificiales, función en la iglesia, tres días de diversiones públicas, representación de tres comedias, sainetes y loas, corrida de toros y arriendo de tablados. Luego de esos tres días, se repetirían las comedias, el teatro y vendrían las diversiones del país: carreras y juego de chueca.

Nada sabemos de esta fiesta, que parece haber sido grandiosa. Las actas continúan con el ritmo acostumbrado y el 1 de enero de 1797 se eligieron los nuevos alcaldes ordinarios. Se copia a continuación el decreto de Fernando José de Urizar, administrador de la renta de correos, postas y estafetas, que ratificaba el nombramiento de Faustino de la Cruz y Bahamonde como administrador de la estafeta de correos de la villa de Talca. También daba cuenta en dicho nombramiento que el quince por ciento del producto líquido de la administración lo asignaba a la villa de Talca y pedía a los diputados del partido que lo auxiliaran en el cumplimiento de sus funciones.

En marzo, los cabildantes acordaron que para que hubiera misa en la cárcel los días de fiesta pedirían limosna a los fieles los domingos. En febrero, se hace referencia a que las leyes del reino no permitían que sujetos ausentes ocuparan oficios concejiles, por ello no era posible que Nicolás de la Cruz (residente en Cádiz) ejerciera por medio de sustituto la alcaldía, por lo que se eligió otro alcalde en la reunión del 1 de abril. El 8 siguiente eligieron alcaldes de la Santa Hermandad. Las siguientes actas son la de la elección de alcaldes del 1 de enero de 1798 y la de nombramiento de nuevos alcaldes de la Santa Hermandad. A continuación, aparece copiado un oficio del presidente de Chile, marqués de Avilés, del 31 de mayo de 1798, dirigido al subdelegado y al cabildo de Talca, en el que les solicita que informen acerca del estado de la población, número de vecinos y su composición, el número de edificios públicos y de particulares (distinguiendo los de techo de teja o paja), iglesias, hospitales, comunidades y conventos, y las rentas provenientes de propios y arbitrios. El cabildo acuerda para dar cumplimiento a esa orden que el alcalde de segundo voto y el alférez real realicen la contabilidad solicitada. El informe, emitido el 20 de julio, fue el siguiente: «casas de teja trescientas doce, de paja ciento sesenta y ocho, total cuatrocientas ochenta incluidos cuatro conventos, iglesia matriz, cárcel y hospital, su vecindario consta de todas layas de gentes, de uno mil veinticinco vecinos, incluidos los cuatro conventos, iglesia matriz 
y cárcel pública, en cuya cárcel subsisten de presos, presas y guardias, ochenta personas». ${ }^{50}$ Los propios de la villa fueron contabilizados en 864 pesos con 4 reales. De esta manera se cumplía con el artículo 120 de la real ordenanza, ${ }^{51}$ que ordenaba al intendente hacer el padrón de los habitantes del partido. La última acta del cabildo presidido por un subdelegado, Juan Ramón de Acereto, corresponde a las elecciones de alcaldes del 1 de enero de 1799.

¿Cómo podemos definir la relación del cabildo con el subdelegado?; ¿qué huellas quedaron en las actas?, y ¿es posible distinguir la actuación del cabildo como cabecera del partido? No hay en las actas constancia de las obras públicas que se llevaron a cabo por iniciativa del subdelegado. Sin embargo, sabemos por otra documentación que la familia del subdelegado impulsó y costeó un hospital para la villa y estuvieron detrás de la obtención del título de ciudad, muy noble y muy leal, para Talca.$^{52}$ Esto articula dos espacios de competencia y confirma en parte lo que la historiografía señala: el cabildo actuó en el casco urbano y el subdelegado en el partido. Sin embargo, hay que matizar. El cabildo actuó como cabeza del partido ante la iniciativa del superior gobierno de desmembrarlo en una nueva subdelegación, aunque no pudieron impedirlo pese a que los vecinos fueron afectados por la pérdida de la fábrica de la concha marina (que era uno de los propios), y recaía sobre ellos exclusivamente el resguardo de los boquetes cordilleranos y la escolta de los presos conducidos a los presidios. Los intendentes no ejercieron sus facultades ignorando a los cabildos cabecera, como se ve en la consulta sobre las necesidades del partido con el fin de destinar la limosna proveniente de la bula de cruzada a las obras públicas que fueran necesarias y el envío de algunas reales cédulas para que tomaran conocimiento. También recayó en el cabildo de Talca, como ciudad cabecera, la obtención de fondos para el pago del sueldo del subdelegado. Con excepción de Álvarez de Acevedo, no hubo una actuación abusiva de los intendentes en el cabildo, aunque impidieron que los miembros de la familia Cruz Bahamonde impusieran nombramientos al margen de la ley. En una acción conjunta de cabildo y subdelegado, se pidió y tramitaron los títulos de ciudad y la creación de un hospital para Talca.

50 Muñoz Correa y Lacoste, 2015, 249-256.

51 Real Ordenanza para el establecimiento e instrucción de intendentes de ejército y provincia en el virreinato de Buenos Aires, año 1782, ANCH, Fondo Varios, vol. 1028, 1786, 127.

52 Carta del Marqués de Avilés, presidente de Chile, a Eugenio Llaguna y Amírola, Secretario de Gracia y Justicia, Santiago, 8 de diciembre de 1797, AGI, Audiencia de Chile, 201. 


\section{Conclusiones}

En Chile, muchos cabildos de villas cabeceras de corregimientos y otros subordinados estuvieron suspendidos y fueron paulatinamente restablecidos a partir de 1770 por impulso monárquico. El de Talca en particular ilustra cómo en una villa recién fundada el corregidor actuó con determinación, denunciando al presidente que algunos miembros del cabildo no respetaban las cédulas de erección y gobierno de la villa. El presidente entonces suspendió el cabildo en 1765 luego de negar la confirmación de las elecciones. Desde entonces, el corregidor gobernó con alcaldes nombrados desde el superior gobierno del reino. Esta etapa finalizó con la intervención real y la denuncia efectuada por el cabildo ante la presidencia de Chile del corregidor (que había sido nombrado por el presidente) por arbitrariedades en el ejercicio de su cargo. Desde entonces, por otra intervención del superior gobierno, el cabildo volvió a elegir a sus alcaldes y no hubo más confrontaciones con los sucesivos corregidores. Respecto a la actuación del cabildo como cabecera del corregimiento, esta posibilidad estuvo dificultada por los oficios de procurador del corregimiento, por lo que desde el superior gobierno se vigiló estrechamente el funcionamiento del cabildo.

La implantación del régimen de intendencias implicó la desaparición de los corregimientos y la creación de las intendencias, que fueron divididas en subdelegaciones o partidos, de menor extensión territorial que los extintos corregimientos. Las facultades de los corregidores pasaron a los intendentes. Si bien la Real Ordenanza de Intendencias contemplaba que hubiera subdelegados de dos y cuatro causas, en pueblos de españoles los primeros y de indios los segundos, la historiografía muestra que esto no se aplicó a rajatabla y que los intendentes y juntas superiores lo adaptaron a las circunstancias locales. Chile no fue la excepción en esta excepcionalidad: todos los subdelegados fueron de cuatro causas. La historiografía ha interpretado que esto supuso una reducción de facultades de los ayuntamientos, que quedaron limitados al gobierno del casco urbano, y generó disputas con los subdelegados. El caso del cabildo de Talca que analizamos no confirma esta conclusión. Por el contrario, en contraste con lo que la historiografía señala, podemos decir que hubo una colaboración entre ambos y que desde la intendencia se consultó al cabildo sobre diversos temas. Las actas muestran que el cabildo supo aprovechar a su favor algunas facultades de los intendentes, como la que le permitía la supresión o extinción de arbitrios, que le fue solicitado. Pero también los intendentes actuaron impidiendo que 
el cabildo impusiera cabildantes sin respetar la normatividad vigente. $\mathrm{Si}$ bien la mayor parte de sus acuerdos abarcaron la villa, hubo otros en los que actuó como cabecera de partido al representarlo (como el caso de oposición al desmembramiento en otro partido), cuando se lo gravó con el sueldo de los subdelegados o cuando pidió que se otorgara a Talca el título de ciudad y de muy noble y muy leal. Volvamos al problema planteado inicialmente: ¿las relaciones entre subdelegados y cabildos fueron conflictivas porque los segundos quedaron reducidos al gobierno del casco urbano? Sin duda hay que ver caso a caso. El cabildo de Talca tuvo más ocasiones de actuar y representar al partido como cabecera de subdelegación que de corregimiento.

Recibido, 6 de octubre de 2020 Segunda versión, 23 de diciembre de 2020 Aceptado, 4 de enero de 2021

\section{Referencias bibliográficas}

Acevedo, Edberto, Las intendencias altoperuanas en el Virreinato del Río de la Plata, Buenos Aires, Academia Nacional de la Historia, 1992.

Agüero, Alejandro, «Ciudad y poder político en el Antiguo Régimen. La tradición castellana», Cuadernos de Historia, 15, Instituto de Historia del Derecho y de las Ideas Políticas Roberto Peña, Córdoba, 2005, 127-163.

Alcauter Guzmán, José Luis, «Régimen de subdelegaciones en la América borbónica. Autoridades intermedias en transición», tesis doctoral dirigida por el Dr. Rafael Diego-Fernández Sotelo, Zamora, El Colegio de Michoacán, 2012.

Alcauter Guzmán, José Luis, Subdelegados y subdelegaciones. Gobierno intermedio y territorio en las subdelegaciones novohispanas, Zamora, El Colegio de Michoacán, 2017.

Alcauter Guzmán, José Luis, «Gobierno intermedio y cohesión territorial con la Real Ordenanza de Intendentes», en Diego-Fernández Sotelo, Rafael; Bernal Ruiz, Graciela y Alcauter Guzmán, José Luis (coords.), Subdelegaciones novohispanas. La jurisdicción como territorio y competencia, México, El Colegio de Michoacán/Universidad Autónoma de Zacatecas/Universidad de Guanajuato, 2019, 23-43.

Bernal Ruíz, Graciela, «Elites, estrategias y alternativas políticas. El cabildo de San Luis de Potosí, 1786-1808», en Machuca, Laura (coord.), Ayuntamientos y sociedad en el tránsito de la época colonial al siglo XIX. Reinos de Nueva España y Guatemala, México, Publicaciones de la Casa Chata, 2014, 99-117.

Bernal Ruíz, Graciela, «Creación de subdelegaciones en la intendencia de Guanajuato, 1790-1810», en Diego-Fernández Sotelo, Rafael; Bernal Ruiz, Graciela y Alcauter Guzmán, José Luis (coords.), Subdelegaciones novohispanas. 
La jurisdicción como territorio y competencia, México, El Colegio de Michoacán/Universidad Autónoma de Zacatecas/Universidad de Guanajuato, 2019, 71-104.

Caño, José Luis, Los cabildos en Indias. Un estudio comparado, Corrientes, Moglia Editores, 2009.

Cárdenas Gutiérrez, Salvador, «Las insignias del rey: disciplina y ritual público en la ciudad de México (siglos XVI-XVIII)», Jahrbuch für Geschichte Lateinamerikas, 39:1, Hamburgo, 2002, 193-216.

Comadrán Ruiz, Jorge, «La Real Ordenanza de Intendentes de 1782 y las declaraciones de 1783. Antecedentes franceses y españoles», en Mariluz Urquijo, José María (ed.), Estudios sobre la Real Ordenanza de Intendentes del Río de la Plata, Buenos Aires, Instituto de Investigaciones de Historia del Derecho, 1995, 11-42.

Dougnac Rodríguez, Antonio, Manual de historia del derecho indiano, México, Universidad Nacional Autónoma de México, 1994.

«El cabildo y Ayuntamiento de la villa de San Agustín de Talca pide se le conceda el título de ciudad» [sin autor], Revista Chilena de Historia y Geografía, 57, Chile, 1927, 373-385.

Enríquez, Lucrecia, «Los jueces diputados y los distritos judiciales borbónicos en Chile (1786-1818)», Revista Chilena de Derecho, 43:2, Santiago, 2016, 643-668.

Enríquez, Lucrecia, «El despertar de los cabildos chilenos a fines del siglo XVIII», Temas Americanistas, 42, Sevilla, 2019, 214-236.

Enríquez, Lucrecia, «De las intendencias a las subdelegaciones: dos momentos historiográficos sobre el régimen de intendencias en la América Borbónica», Historelo. Revista de Historia Regional y Local, 12:25, Bogotá, 2020a, 83-217.

Enríquez, Lucrecia, «Cabildos, elites e intendentes en Chile», Fronteras de la Historia, 25:2, Bogotá, 2020b, 36-56.

Lorenzo, Santiago, «El corregidor chileno del siglo XVIII», Historia, 32, Santiago, 1999, 131-139.

Lorenzo, Santiago y Urbina, Rodolfo, La política de poblaciones en Chile durante el siglo XVIII, Quillota, El Observador, 1978.

Machuca, Laura, «Cabildo de Campeche versus subdelegados, 1791-1796», en Diego-Fernández Sotelo, Rafael; Bernal Ruiz, Graciela y Alcauter Guzmán, José Luis (coords.), Subdelegaciones novohispanas. La jurisdicción como territorio y competencia, México, El Colegio de Michoacán/Universidad Autónoma de Zacatecas/Universidad de Guanajuato, 2019, 219-236.

Muñoz Correa, Juan Guillermo y Lacoste, Michelle, «Actas del cabildo de la villa de San Agustín de Talca (Reino de Chile, 1759-1815)», Revista Iberoamericana de Viticultura, Agroindustria y Ruralidad, 5, Santiago de Chile, 2015, 156-265. 
Palomo Souza, Carmen, «Los corregidores de Zacatecas: una elite de poder (17001786)», en Ruíz Rivera, Julián y García Bernal, Manuela (eds.), Elites urbanas en Hispanoamérica (de la conquista a la independencia), Sevilla, Universidad de Sevilla, 2005, 115-132.

Piña Homs, Román, «Ordenanzas para corregidores y alcaldes mayores dadas por las autoridades indianas», Memoria del X Congreso del Instituto Internacional de Historia del Derecho Indiano, México, 1995, 1205-1219.

Tau Anzoátegui, Víctor y Martiré, Eduardo, Manual de Historia de las instituciones argentinas, Buenos Aires, Librería Histórica, 2005. 